\title{
The Challenges of Modern Society and the Scientific Vector in Art Education
}

\author{
Svetlana Anisimova-Tkalich \\ Art-graphic Faculty \\ Moscow State Pedagogical University \\ M.Pirogovskaya str.1/1, 119991 Moscow \\ Russian Federation \\ e-mail: amguema2016@mail.ru \\ Aleksey Tkalich \\ Department of tourism \\ St. Tikhon's Orthodox University of Humanities \\ Ilovajskaya str.9, 115184 Moscow \\ Russian Federation \\ e-mail: tkalichai@mail.ru
}

\begin{abstract}
Today, higher education institutions in Russia need teaching staff who are competent in matters of scientific training and counselling students and young scientists. The necessity of changes in the system of professional training of teachers, researchers, consultants, and experts is one of the important landmarks of educational science and practice. Master's degree programme in high school performs the function of transition technology between the development of basic professional templates in Bachelor's programme and the formation of master's student motivation to search activities and the presentation of student scientific research projects in short. Cultural and language design technology: culture is one of the priceless treasures of humanity. However, this treasure often lies without use. Innovative tools, analytical screening models and coding information systems offered by experts are generally neutral with respect to culture or even suspended from it. Cultural and neutral methods allow the information strategy of the socio-cultural development of society to form quickly its own space of communication, which does not perceive any ethical, aesthetic, and moral restrictions. When the task is to endow products with a radically new meaning and offer other rationales for its acquisition, cultural-neutral methods are completely helpless. At the same time, the cultural and linguistic design technology is devoid of synergistic abilities of human exposure. Scientific vector of environmental design culture: we focus on the paradigm of ecological design culture. This determines local regional cultures as one of the important national-cultural sources. A standard approach to the study of artefacts of traditional culture cannot meet the language needs of the ecological design culture. The design industry is constantly looking for new artistic and imaginative ideas. Universal formulas quickly become known to everyone; products lose their brand identity. Competition having access to universal resources is being increased. In many respects, we agree with the authors of the works. However, the issue is addressed at the global and theoretical level. We believe that the search for sustained technology leadership in education should be guided by the principles of methodological approach. In this regard an important factor we provide practical experience and its scientific design: abstracts, formulas, artistic metaphors.
\end{abstract}

\section{Introduction}

Leadership as a form of a student's self-actualization is partially reflected in the plans of morale building activities of the educational institutions (Lac and Cumings Mansfield 2018). These are volunteer programs, patronage work with the older generation, children in nursery schools and medical institutions (Bushman and Fagan, 2018; Sorokina 2018). But the morale building activities with youth puts aside the scientific vector of leadership in artistic education.

Formation of motivation for leadership in science in the Master's Degree students in the area of the future profession requires particular attention (Wenner and Campbell 2017). Amorphous mechanism of formation of leadership in science is reflected in the status of the education institution (Avilova et al. 2015). The success formula can be implemented in the environment of the organized vivid interest in scientific developments of teachers and students.

Negative trend 1. The notion of "scientific leadership" in artistic education poorly correlates with the needs of the modern society and social and economic development strategies of the country. 
The leadership in artistic education depends in the organized program of scientific developments popularization in the institutes. The cultural and educational strategy of the education institution with pedagogical dominant is realized in the frameworks of the training program. The morale building methods are remembered after graduation and for many years.

Today, the gap between the cultural education, professional education of a future teacher in artistic education and formation of leadership skills in science is dictated theoretically.

Negative trend 2. The negative trend of "archivation" of the scientific results goes back to the $20^{\text {th }}$ century when the expert board members were not confident in the author of thesis research. The negative trend of "archivation" has covered the up-to-date situation.

Sometimes, no one in the faculty, except for a small group of teachers-experts, knows what scientific successes have been achieved by the Bachelor's and Master's degree students. Every year, tens and hundreds of graduating students get Master's Degree Diplomas, but we know too little about those developments made in their graduation works.

A young scientist should search for opportunities to promote his conceptual model or a new technique. The scientist should draw the youth's attention to the topic of his research. He publishes articles, monographs, prepares poster papers for thesis projects. This is how the active tactics of the leader in science is demonstrated. And it is necessary to form these qualities of the artistic students starting from the first year of study.

The creative vector has a variety of images. Stroke of insight drives the author, gives strength and confidence in selecting the style, line of character or theme of the script. The scientific vector is demonstrated in thinking. It is necessary to prepare the Master's Degree student for public speech as if he would be a starting artist: articulation, speech tempo and rhythm, tonality, voice level near microphone, visual communication with audience, appearance, colour of garment pieces and body posture. The scientific component of speech is formed from terms, logics of report and author's novelty. The public speech with scientific report requires such skills, as confidence, commitment, knowing of terms.

The glossary of media in art is supplemented today with new notions. For example: principle of additional reality, web-visualization, virtual museums, drone shooting, radical democratization of access to cultural inheritance, platform of ethnographic and technological interaction, temporal dimension. They create new semantic space of science, education, and culture. The educational result in artistic education is formed in the students' consciousness and reflected in the course of task preparation. The scientific developments create a good scientific reputation of a faculty, institute, university. However, many Russian institutes are no satisfied with the current situation in the international rating.

\section{Literature review}

Becker (2015) stresses the important factor that education in the Liberal Arts and Sciences model is considered as a system of higher education, which entails disciplinary breadth of coverage and depth of study selected subjects. Features of this system are oriented towards teaching students, as well as academic and administrative infrastructure to promote the full training.

Of great interest is the work of a foreign author Verganti (2018). Author of scientific work stresses the important factor that a new function of design consisting of the notions forming a new attitude to the domestic culture and environmental culture. The author sets the following questions to the reader: "How to overcome the paradox of idea? In what a way to be engaged in design in the world full of opportunities?". The information noise makes it difficult to search for creative and scientific niche for the applied Master's degree students. In this context, the problem of professional training of specialists, including art teachers, creative industry specialists, has several sources.

Author of scientific work stresses the important factor that the problem of professional training of specialists, including art teachers, creative industry specialists, has several sources. It should be remembered to the students that "the old system valued the tradition and homogeneity, and for the new system, the differences are more important" (Seabrook 2017).

Russian authors are also studying this problem. In the Russian design education, the design project culture model consisting of the following three technologies has been established: ideologic valuable, social valuable, and cultural language ones. The defence of thesis is, as a rule, based on interpretation of the mentioned technologies that are important for positioning valuable indicators of the design proposal.

"Examines the concept of liberal arts (in the Russian tradition - model education of liberal arts and Sciences) is one of the most famous variants of integrated academic reform aimed at, according to its authors, address simultaneously a number of before higher education issues" (Ivanova and Sokolov 2015).

In many respects, we agree with the authors of the works. However, the issue is addressed at the global and theoretical level. We believe that the search for sustained technology leadership in education should be guided by the principles of methodological approach. In this regard an important factor we provide practical experience and its scientific design: abstracts, formulas, artistic metaphors. The experience shows that the most rememberable 
"formulas" for students of the creative pedagogical institute are: principles, methods, thesis. Today, the majority of the Russian language works is devoted to mastering the computer skills, opportunities to construct training presentations. Great attention is paid to the skills of digital educational resource development. The important aspect is also the training of organizers for working with the youth.

\section{Research design and main outcomes}

Question: what mechanisms do restrain the dynamics of the breakthrough of scientific connotations in artistic education? The existing problem needs to be specified with detailed review of dynamics-restraining barriers. Building the leadership in science in the practice of artistic education is of great interest for creative industry. In the current situation, the features of psychology of designers expressed by continuous search for a new element to express the media in art idea is also an important topic to study.

Many Master's Degree students when preparing the public speech show a mismatch in psychological state (doubt in the uniqueness of their "stroke of insight") and need in public substantiation of novelty, its pragmatic value. For example, in artistic education, searching for scientific vector in the intersection of applied pedagogy, variety of styles, and art of persuasion is a problem for many students.

It can be said that the pedagogical science in artistic education reflects challenges of the modern society. The problem of poor orientation of the students in artistic education towards the leadership in science reflects lacking correlation between challenges of the modern society and existing navigator of particular actions at all stages of educational process.

\section{- Universal methodological model to eliminate risks in art education}

The increasing role of science in education leads to leadership in education. It is important to promptly and creatively to correlate the internal resources and external demands of modern digital society with administrative orders. Pedagogical universities can use variation and integration of scientific and methodological tools. Each institution relies on specific indicators of professional specificity of training students. For example, "academic painting", "academic drawing", "graphic design", "multimedia design", "media technology in art".

Today the creation of condition for building scientific and pedagogical leadership in art education requires a methodological model of joint efforts of administration, consultant teachers and Master's Degree students. We offer a universal methodological model. This model can include several tactics blocks: theoretical, practical and auxiliary. And the number of areas of professional training is not limited. For example, in art education, it is important to form motivation for scientific developments of future teachers, designers, specialists in work with creative youth, consulting teachers on the works with pre-school kids. Block of theoretical and methodical activation of training and educational space in the educational institution:

- inventive methods of formation of leadership motivation;

- reverse method of teacher and student communication;

- $\quad$ set of tasks and requirements for novelty protection.

Block of scientific and practical activation of training and educational space in the educational institution: method of informational aesthetics (reliability) of search results, method of metaphorical transfer of events to author's objects in the project, set of tasks and requirements for novelty protection.

Block of auxiliary information for personal search routes of the Master's degree students in the educational institution (with graphical culture as an example):

- geoinformation map of the Russian cultural landscapes,

- graphical achievements-communicative for the peoples of Russia,

- $\quad$ set of tasks and requirements for novelty protection.

The notion of "information noise" is introduced by Seabrook (2017). Information noise means a public domain, indicator of freedom of thoughts, ideas, opportunity for a person to enter the virtual scene of the multichannel communication. Similarly, the methods of navigation action scheme can be predicted to form the interest to scientific developments:

1) Creation of the information noise environment on the basis of daily notification of the Master's Degree and postgraduate students about scientific developments:

- organization of audio programs,

- interview with experimental project participants,

- interview with experimental project teachers and authors. 
2) Creation of conditions for implementation of the model "Oral Journal of Student Scientific Research" for the purposes of public presentations of scientific developments of the Master's Degree and postgraduate students:

- demonstration of video fragments on the topic of the students' scientific developments,

- preparation of personal presentations for public speech,

- organization of training on formation of the skill of oral speech on the topic of research in "standup" format (15-minute presentation with the use of scenography, media tools, video fragments).

3) Creation of the "reverse technology" environment for consulting teachers and students communication for monitoring purposes:

- organization of the monitoring schedule,

- development of requirements for monitoring process participants,

- explanation of objectives and importance of the monitoring for presentation of scientific developments of the Master's Degree and postgraduate students.

In the art education, the art history, design and media, media in art should be based on the scientific format of interaction. For example, the students' media product requires explanation of the author's innovation with the use of relevant scientific terms. The glossary of scientific schools in art education is an important factor for building leadership in scientific perception of the modern art education.

Many scientific schools have no unified guideline in the form of glossary with definitions within a faculty or institute. For the Master's Degree students, in art education, it is important to know both academic formal standards and new connotation constants of scientific design. The presentation of Master's Degree works in art education without due regard to the modern scientific connotations and developments indicates the issue of incomplete research.

Specificity of our idea is that the block of auxiliary information "navigator of particular actions" introduces a valuable indicator of pragmatics. The efficient indicator of pragmatics is supposed to be a cultural and language design technology. This indicator, the cultural and language design technology, will provide for stability of pedagogical requirements to improve the qualitative indicator of scientific developments of the Master's Degree students, the prospective postgraduate students. We think that the important factor of mastering the cultural and language design technology is the topic of the projects:

- ethnic art sources of the modern design

- nature and culture of local areas,

- ethnic design in media in art projects,

- graphics of traditional culture in the art objects of the modern design.

International vector of the cultural and language design technology opens a new page in the Master's degree and postgraduate education. Transfer of natural and cultural features of the country recorded in graphics, to the modes design objects using the "design metaphorical image" method helps students to demonstrate the efficiency of their search in panoramic media scenes. Such works are exclusive. For example, the natural and cultural features Thailand, features of the Chinese traditional suit, features of ethnic art attainments in local areas of Russia.

\section{- Scientific research component in graduation project}

The hypothesis: pedagogical innovation can be realized at an educational institution if it is developed and proposed by the students sustained methodological complex with an innovative element. It is this innovative element creates an atmosphere of creativity in art education that leads to professional leadership. The methodological model of research in the media in art graduation work will be purposefully formed on the basic component, cognitive and search component, innovation component in the form of scientific formulae. The terminology of the innovation component can be represented in the form of formulae reflecting new connotations:

a) local communications of the graphical schools;

b) communicative signal of cultural inheritance (visual, audio, and sensor);

c) method of metaphorical transfer of elements of traditional graphical culture on the design object;

According to this principle of "formula differentiation" of innovations, the local and regional series of knowledge retrieval digital resource for media in art can be created.

The presentation of the digital educational resource on regional studies, geography, modern history of arts of $20^{\text {th }}$ century, and history of design without regard to such elements of graphical history, as petroglyphs, pictographic messages in the preliterate period, peculiarities of handwriting and decorative initials will not become a cultural event in pedagogy. The author of the informational educational digital resource cannot fully provide the visual versatility of the heritage of multinational Russia without colour effects of natural landscapes (steppe, meadow, mountain) in different seasons. 
Preparation of the modern educational digital resource requires from the teacher to have more extensive knowledge about cultural heritage in local areas and media culture as compared to the traditional preparation of the training book on the subject.

The effect of teaching the Bachelor's Degree students is represented by knowledge in the history of arts and computer technology. This scope of knowledge at the next stage of the Master's Degree education is not sufficient for development of the regional or federal projects. The federal or regional project should have a variety of national and cultural components in the areas of the Russian Federation. This is perceived today as the marketing start for educational product promotion in the international pedagogical space. The cultural and natural landscapes of the regional local territories give birth to metaphorical turns, symbols imagery and colorization reflecting the visual and audio differences that are actively perceived both by pupils and Bachelor's and Master's Degree students.

The inventive contribution of the graduating student in the course of defence of the master's thesis can be implemented in the form of educational digital resource for the educational institution. Such contribution gives for designers a potential of practically passive fractal of heritage in local areas. The information aesthetics of the transfer of the local heritage is, first of all, its reliability. Meeting all the above requirements will ensure recognition of the inventive contribution of the applied Master's Degree graduating student.

\section{- $\quad$ Research Methods}

In the modern reality, a spontaneous virtual intersection of different humanitarian knowledge and technical skills is observed. In such conditions, only the versatility of knowledge creates the platform for growing a "portfolio of ideas", unique author's formulations. It provides for increasing responsibility of teachers and students for formation of the scientific rating of the faculty, institute on the basis of the public recognition of new connotations of scientific design. The combination of visualization means for connotative and art focus of the graphical product is unlimited for creative experiments.

Risk zone. The boundary between the instrumentation skill of the Bachelors reflecting the area-specific training (as the executor) and leadership wish for successful search of the Master's Degree graduating students is not sufficiently developed, on out opinion.

The culture of the ecological design shows the reflex to "forecasting" of the increasing social and pragmatic value of the national and cultural markers. The uniqueness of the local markers allows to form prospective modelling in the frameworks of training of designers for tourism and education, and commercial stability of the regions of multinational Russia.

The educational effect of tasks with research component is based on the learning methods:

1) learning method of research stage differentiation - fundamental difference of methodological steps between levels: Information search, collection, structuring, innovative combination of research results in pragmatic scenes of media product,

2) practical wording of the author's versatility of approaches to identification of graphical style in the specified geographic areas,

3) wording of innovative method on the basis of "terminology tolls" that details the essence of the innovation (for example, differences in the culture of local areal have traditional artefacts in the form of pictographic messages, petroglyphs on the rock, male and female tattoo).

Let us name number of industries where national markers of graphical achievements in local areas of Russia are demanded: "scientific tourism" routes, fashion and textile design, souvenir production, art objects of small architecture, ecological villages, landscape design, printed products for children and adults, advertising materials with symbols of the territory.

The final results were that in the course of work, the applied Master's degree students succeeded to realize the experimental projects with national and cultural component.

\section{Conclusions}

In many respects, we agree with the other authors studying the same subject as the one tackled in our paper. However, the issue is addressed at the global and theoretical level. We believe that the search for sustained technology leadership in education should be guided by the principles of methodological approach. In this regard an important factor we provide practical experience and its scientific design: abstracts, formulas, artistic metaphors. Leadership in education we have determined how conceptual modelling copyright teaching modules with scientific dominant. Search and conversion of legacy design industry or scientific tourism industry only begins its route. The main thing is that this route developed. Modern design has a huge advantage at the international level when using natural and cultural heritage.

Theme convert graphic heritage regional industry design was seen in the works of authors. This theme brings together national colour culture design industry and tourism. It is very important to develop in the 21 st century scientific tourism routes. For example, there are the navigator partnership activities for fixing artistic and graphical indicators of the cultural landscape of the territory (Tkalich and Tkalich 2016). The scientific vector in art education 
covers a wide range of new knowledge and practical skills. It discovers risk zones not known before. For example, one of the problems, as we see, is lacking compatibility of functional, cultural and educational components in the training modules. The issue is rather difficult and it remains open for new proposals and discussions. The increasing gap between the reality and illusive virtuality, observed asynchrony of humanitarian and technical knowledge is a dangerous trend.

The offered set of thesis gives the navigations benchmarks for new routes of scientific approach in art education. Scientific achievements-steps to leadership in art education: Brief historiography of professional stages of activity. The basis and conviction of the monograph's authors in the relevance of the scientific vector in design is the study of many years, of experience in the departments of higher education (Moscow region), where they train tourism managers, teachers of art education, organizers of cultural and educational work in social and cultural institutions.

An important stage of "professional maturity" is research and teaching activities in the Far North-East of Russia (1989 - 1999). The objects of study determined forms of traditional and modern theatrical creativity in various genre modifications: national theatre, folk theatre. The model of the original directorial work "PerformansDUO" was presented at the international festival of national cultures (Canada, Weithorse 1992).

The result of the author's cascade technology (from the initial stage of large-scale research to the interpretation of its cultural and linguistic achievements) in the projects of students of Bachelor's and Master's programmes demonstrates as follows:

- seminars and creative laboratories of masters of traditional schools (1990-1994, Magadan, Chukotsky Avtonomny Okrug / ChAO), ChAO),

- works of students of the Higher Pedagogical School of the Peoples of the North (1995-1997, Anadyr, Region:

- graduate and experimental projects of students of higher educational institutions of Moscow and Moscow

- Moscow State University of culture and arts (2000 - 2008),

- Institute of Fine Arts / Graphic Art Faculty of Moscow Pedagogical State University (2016 - 2019).

\section{Acknowledgements}

The authors would like to express their gratitude to the management of educational institutions of higher education, where they could carry out experimental classes with students of faculty "design".

\section{References}

Avilova ZN, Gulei IA, Shavyrina IV (2015) Formation of the customer-centric organizational culture of the university as a factor of effective social and economic development of the region. Mediterranean Journal of Social Sciences 6(3 S5):207. doi: 10.5901/mjss.2015.v6n3s5p207

Becker J (2015) The system of education of liberal arts and Sciences: responding to the challenges of the twentyfirst century. The Journal Educational issues 4: 33-61. doi:10.17323/1814-9545-2015-4-33-61

Bushman B, Fagan MK (2018) Public Library Programs and Accommodations for Deaf and Hard-of-Hearing Children in the United States. The Journal of Deaf Studies and Deaf Education 24(2):74-83. doi: 10.1093/deafed/eny041

Ivanova UV, Sokolov PV (2015) Prospects for the development of education in the Liberal Arts and Sciences model in Russia. The Journal Educational issues 4: 72-91. doi:10.17323/1814-9545-2015-4-72-91

Lac VT, Cumings Mansfield K (2018) What do students have to do with educational leadership? Making a case for centering student voice. Journal of Research on Leadership Education 13(1):38-58. doi: $10.1177 / 1942775117743748$

Seabrook J, Marketing culture, 1st edn. (Ad Marginem Press: Moscow, Russia, 2017), 240 p.

Sorokina AL (2018) Innovative Development of Education Strategy in Russian Federation: Experience of Future Skills School Graduates Formation by City Organizations Network Interaction. European Journal of Education 1(1):17-29. doi: 10.26417/ejed.v1i1.p17-29

Verganti R, Innovation, guided design. Design-Driven Innovation, 1st edn. (Delo: Moscow, 2018), 384 p. 
Wenner, JA, Campbell T (2017) The theoretical and empirical basis of teacher leadership: A review of the literature. Review of educational research 87(1):134-171. doi: 10.3102/0034654316653478

Tkalich SK, Tkalich AI (2016) Navigator partnership activities for fixing artistic and graphical indicators of the cultural landscape of the territory. Materials of the International scientific and practical conference 'European Review of Social Sciences', pp. 64-78 